\title{
A RARE CAUSE OF HYDROENPHROSIS: CASE PRESENTATION OF AN INTRATHORACIC HERNIATED URETER
}

Ibrahim Alkhafaji ${ }^{1}$, Ehab Abusada ${ }^{1}$, Adam Jones ${ }^{1}$, Mooyad Ahmed ${ }^{1}$, Talal Jabbar ${ }^{2}$, Omar Al-Mula Abed ${ }^{1}$

${ }^{1}$ East Lancashire Hospitals NHS Trust, United Kingdom

${ }^{2}$ North Bristol NHS Trust

Corresponding author: omar.mulaabed@gmail.com

Submitted: July 30, 2020. Accepted: November 20, 2020. Published: March 3, 2020.

\begin{abstract}
\section{Background}

Thoracic ureteric herniation is an uncommon finding with a varying presentation. Since its first documentation in 1958, few case reports have been published, and there is no consensus on its management. This condition is typically asymptomatic, with most cases identified incidentally from cross-sectional imaging or discovered intra-operatively.

As a result of differing presentations and a lack of consensus or evidence of best practice, this rare finding's management is not defined. This can range from adopting a conservative approach to more invasive measures such as ureteric stenting or pyeloplasty to repair the thoracic hernia.

The authors present a case of thoracic ureteric herniation in a 74-year-old male presenting with rightsided abdominal pain. This patient was known to have a diaphragmatic hernia following pulmonary fibrosis investigations and chronic obstructive pulmonary disease (COPD). At presentation, there was acute kidney injury (AKI), and subsequent computed topography (CT) demonstrated right-sided hydronephrosis and perinephric fat stranding. This was caused by ureteric obstruction with a transition point at the site of thoracic herniation. The patient was successfully managed with retrograde ureteric stent insertion.

This case report aims to highlight variance in the presentation of ureteric thoracic herniation and discuss management options. There is no consensus on management for this condition and choices dependant on specific symptoms and patient factors to the best of our knowledge.
\end{abstract}

\section{INTRODUCTION}

Ureteric herniation is extremely rare, with less than 200 cases reported in the literature. Ureteric herniation can vary and is usually classified by the site into where it herniates. These include uretero-inguinal, ureterofemoral, uretero-sciatic and intra-thoracic hernia. ${ }^{1}$ The exact prevalence and distribution of these types of ureteric herniation have remained unknown. The latter occurs through a diaphragmatic hernia defect and is the rarest type, and since it was first recorded in $1958,{ }^{2}$ only 10 cases have been reported in the literature.
In general, diaphragmatic hernia is a congenital anomaly occurring due to incomplete closure of diaphragmatic muscles, at various degrees, during prenatal development. It is classified according to the anatomical variation. The first type is a Morgangni's hernia which occurs when there is a defect at anterolateral point beneath the sternum, and potentially this may cause herniation of intraperitoneal organs into the thoracic cavity. The second type is known as a Bochdalek hernia, with the defect at the diaphragm's postero-lateral aspect. This may cause herniation of 
retroperitoneal organs that would include the kidney and ureter.,

The majority of ureteric thoracic hernias have been diagnosed incidentally with either cross-sectional imaging or discovered intra-operatively. A limited number of cases have presented acutely with ureteric obstruction secondary to either ureteric stone or incarceration of the ureter at the site of herniation. ${ }^{5}$

As a result of the disease rarity and lack of highlevel evidence, there is no consensus on the management of this uncommon finding. Management is varied, and patient symptoms and comorbidities and performance status should be taken into account. Available treatment options will include retrograde stenting, nephrostomy, or surgical intervention using laparoscopic or open reconstructive approaches to repair the diaphragmatic hernia. ${ }^{3,4,6}$

\section{CASE PRESENTATION}

A 73-year-old male presented to the emergency department (ED) with a two-day history of localised right flank pain. The patient had no fever or lower urinary tract symptoms. There was no history of nephrolithiasis. The patient had significant comorbidities that included COPD, pulmonary fibrosis secondary to asbestosis, ischaemic heart disease, and hypertension. He had previously been under the care of urology in 2003, having had investigations for haematuria. At the time, an intravenous urography commented on an abnormal shape to the right kidney only. Given that he was asymptomatic, there were no further investigations for this, and the patient was discharged from urology.

At presentation, clinical observations demonstrated tachycardia ( 95 beats per minute), tachypnoea, reduced oxygen saturation at $94 \%$ on air, blood pressure of $127 / 93 \mathrm{mmHg}$, and a temperature of $35.1^{\circ} \mathrm{C}$. The examination was remarkable for right-sided renal angle tenderness only, no signs of peritonism and his bladder was not distended. Rectal examination demonstrated a large benign prostate. Urine dipstick was positive for erythrocytes at 300/HPF only and was negative for leucocytes and nitrates. Routine blood tests revealed a raised white cell count at $15.210^{9} / \mathrm{L}$, raised C-reactive protein at $78 \mathrm{mg} / \mathrm{L}$, and acute kidney injury with creatinine $134 \mathrm{umol} / \mathrm{L}$ and eGFR $45 \mathrm{ml} /$ $\mathrm{min} / 1.73 \mathrm{~m}^{2}$ (baseline $>90 \mathrm{ml} / \mathrm{min} / 1.73^{2}$ ).
The initial working diagnosis was right pyelonephritis based on the clinical finding of right renal angle tenderness with raised inflammatory markers and urinalysis findings. The patient was initially managed with intravenous fluid replacement therapy, intravenous gentamicin, and then admitted under the urological team. Following the urology team's assessment, the patient had an urgent non-contrast CT scan of the abdomen (CT-KUB) to rule out ureteric obstruction due to a ureteric stone. CT KUB reported a large right Bochdalek hernia with severe right-sided hydronephrosis and peri-nephric fat stranding secondary right ureteric obstruction with a transition point at the site where the ureter is crossed the diaphragmatic defect (Fig 1A,1B).

The patient was listed for emergency cystoscopy, right retrograde pyelography, and ureteric stent insertion to relieve the obstruction and prevent worsening kidney function and sepsis. Intra-operatively, a retrograde pyelogram (Figure 2A) confirmed the CT-KUB findings of a herniated ureter. However, the renal pelvis could not be accessed as there was difficulty navigating the pelvi-ureteric junction with both a polytetrafluoroethylene (PTFE) guide wire and straight-tip complete hydrophilic guidewire (Terumo) due to a narrowed and tortuous anatomy. Nevertheless, access to the renal pelvis was achieved using a super-stiff (Amplatz) guidewire to the proximal ureter (Figure 2B) and then a curved-tip complete hydrophilic guide wire (Terumo) following retrograde pyelogram to confirm the position of the convoluted proximal ureter and renal pelvis (Figure 2C). A $6 \mathrm{Ch}$ multi-length ureteric double pigtail stent was then inserted in standard fashion using a PTFE guidewire (Figure 2D).

Post-operatively, the patient continued intravenous antibiotics initially, followed by an oral equivalent. The blood tests showed an improvement of renal function and inflammatory parameters following the ureteric stent insertion, and the patient was successfully discharged on day three post-operatively with oral antibiotics.

Following discussion at the departmental uroradiology meeting, it was agreed that the patient would be managed with long-term ureteric stent placement with six monthly stent changes. Open or laparoscopic 
FIG. 1 Images of the computed tomography (1A coronal) and (1B axial) sectional images demonstrate the hydronephrosis with surrounding inflammation in the right kidney and clearly show the herniated part ureter through the diaphragm.

(A)

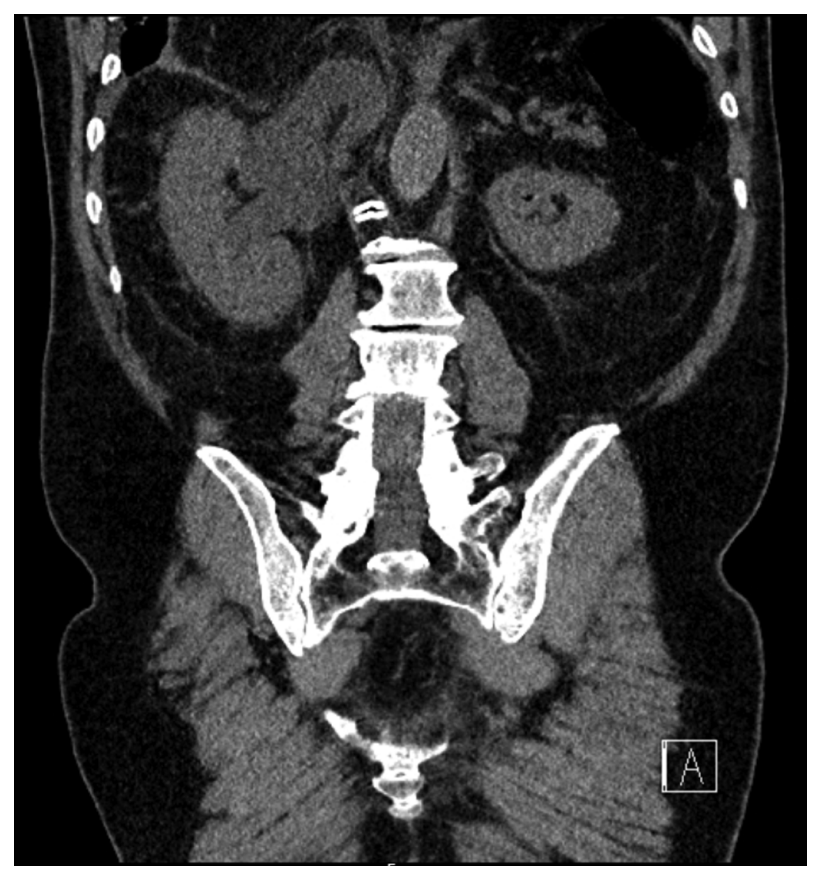

diaphragmatic hernia repair was deemed to carry significant risk for this patient due to his comorbidities and poor performance status. The patient was in agreement with the proposed management plan

The patient was re-admitted two months following initial ureteric stent insertion with an infective exacerbation of his COPD and was managed on the intensive care unit for intensive respiratory support. He failed to respond to treatment, developed respiratory failure, and subsequently died during the same admission.

\section{DISCUSSION}

Thoracic herniation of the ureter is rare. Since the first published case in 1958, there have only been 10 cases in the literature. Among this published cohort, the majority described that thoracic herniation of the ureter to be a phenomenon found in elderly patients. It was also recognised that thoracic herniation of the ureter is an incidental finding, often on cross-sectional imaging or rarely intra-operatively. ${ }^{7}$
(B)

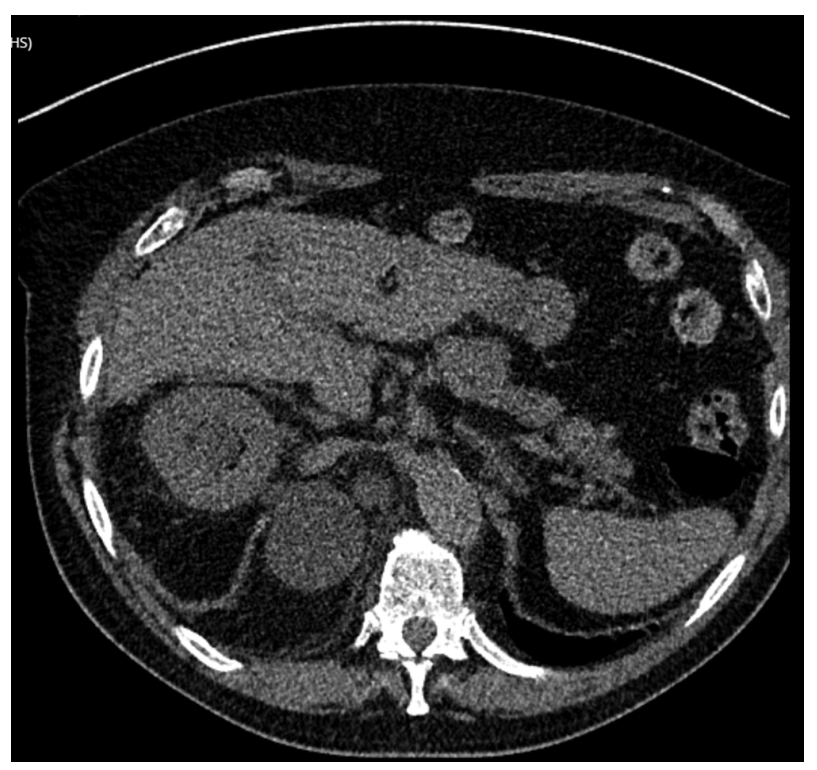

Treatment options for this rare condition are variable with no clear consensus. It is usually decided according to the patients' presentation and their general status though most are managed conservatively. If indicated due to symptoms or compromised renal function, surgical intervention can range from minimally invasive ureteric stenting or nephrostomy to more complex reconstructive laparoscopic surgical repair of diaphragmatic hernia. The latter is typically reserved for the patient with good-functional capacity and performance status with few comorbidities. ${ }^{4,5,8}$ Despite this, due to a lack of cases and thus no highlevel evidence, there is no accepted gold-standard to treat such patients.

A few reported cases of thoracic ureteric herniation cause sepsis, loin pain, and haematuria. Some of the reported instances describe their surgical technique. Lin et al. describe a case managed with retrograde ureteric stent insertion using an amplatz guidewire. Lin et al. also reported that upon subsequent exchange of ureteric stent, that there was the migration 
FIG. 2 Intraoperative images showing retrograde pyelogram delignating the herniated ureter and dilated renal system (2A) and the initial cannulation with a PTFE guidewire (2B). Further calculation with haterumo guidewire passing into the renal pelvis and lower group calyces (2C) while (2D) is the final image confirming the proximal end of the ureteric stent coil in the renal pelvis.

(A)

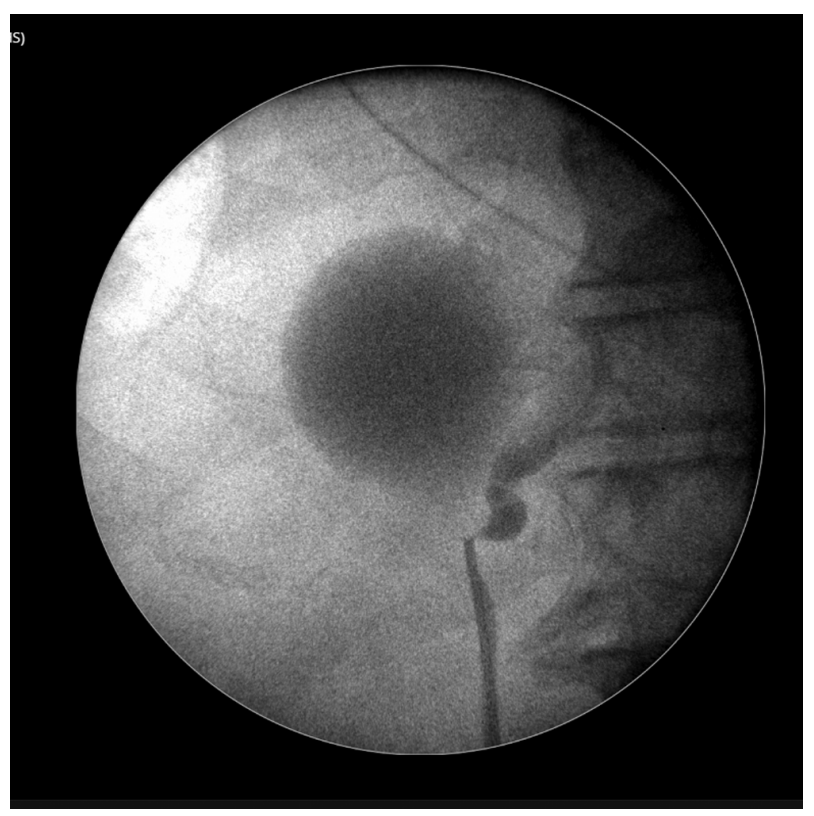

(C)

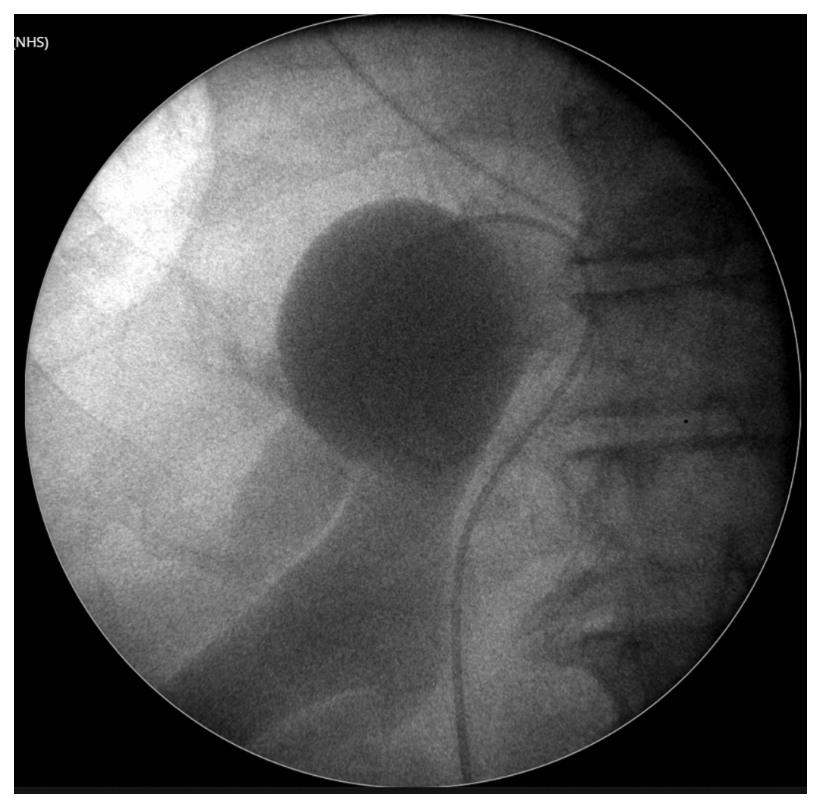

(B)

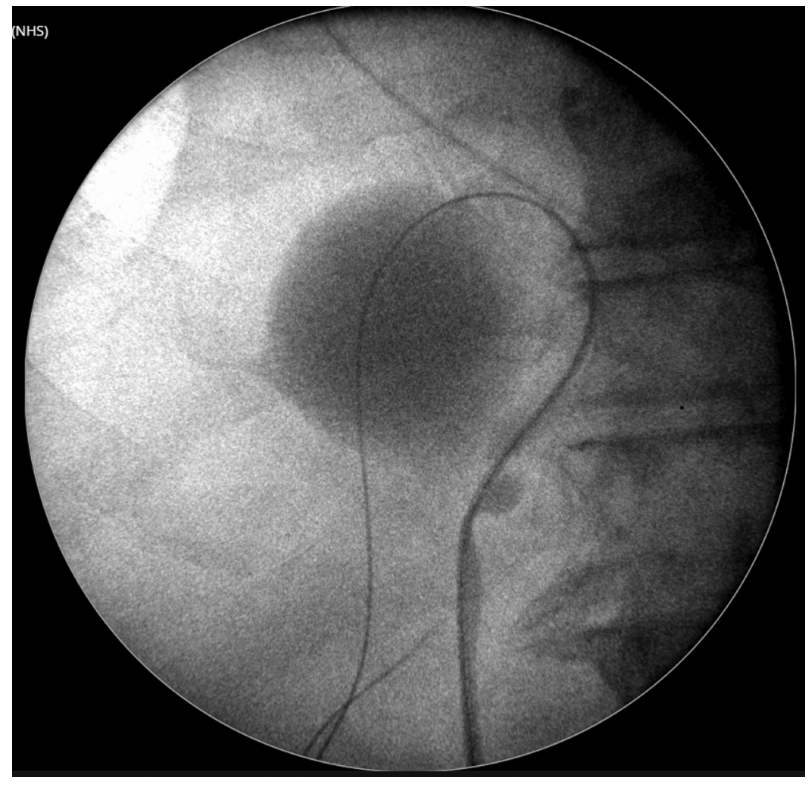

(D)

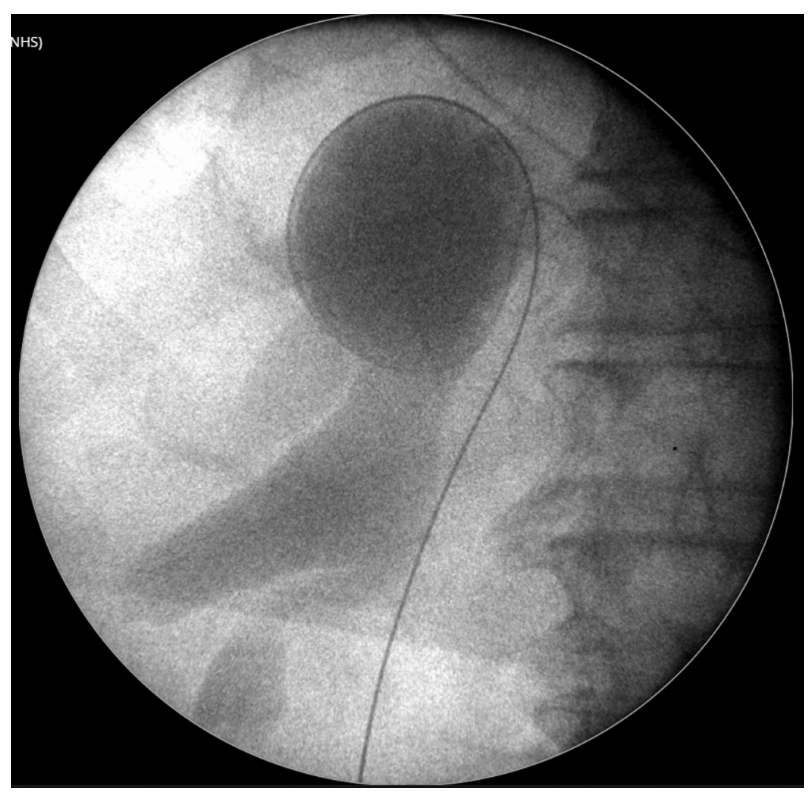


TABLE 1 Summary of the Management Experience in the Current Available Literature

\begin{tabular}{|c|c|c|}
\hline Authors, Year & Age and presentation & Treatment \\
\hline $\begin{array}{l}\text { Dru et al. } \\
20163\end{array}$ & $\begin{array}{l}\text { A 94-year-old female presented with sharp right } \\
\text { flank pain. Imaging demonstrated herniation of } \\
\text { the right renal pelvis and proximal ureter into a } \\
\text { large diaphragmatic hernia. }\end{array}$ & $\begin{array}{l}\text { Symptoms were controlled by only ureteric } \\
\text { stent insertion }\end{array}$ \\
\hline $\begin{array}{l}\text { Shekar et al. } \\
20198\end{array}$ & $\begin{array}{l}\text { A } 78 \text {-year-old male presented with persistent } \\
\text { right flank pain. CT revealed suspect } \\
\text { diaphragmatic (Bochdalek) hernia with right } \\
\text { renal pelvis and upper ureter as contents. }\end{array}$ & $\begin{array}{l}\text { Laparoscopic mesh repair of hernia with } \\
\text { ureter reconstruction. }\end{array}$ \\
\hline $\begin{array}{l}\text { Lin et al. } \\
20175\end{array}$ & $\begin{array}{l}\text { An } 81 \text {-year-old female with flank pain who was } \\
\text { found to have idiopathic diaphragmatic hernia } \\
\text { with an incarcerated proximal ureter. }\end{array}$ & $\begin{array}{l}\text { Initial ureteric stenting, then subsequent } \\
\text { open diaphragmatic hernia repair and } \\
\text { ureteric reconstruction due to difficulty in } \\
\text { stent exchange and stent symptoms. }\end{array}$ \\
\hline $\begin{array}{l}\text { Beland et al. } \\
20186\end{array}$ & $\begin{array}{l}\text { An } 84 \text {-year-old female incidentally found to } \\
\text { have herniation of the right ureter through } \\
\text { the diaphragm with an } 8 \mathrm{~mm} \text { obstructing } \\
\text { proximal ureteric stone with upstream moderate } \\
\text { hydronephrosis. }\end{array}$ & $\begin{array}{l}\text { Treatment was challenged with a high level } \\
\text { of operator skills needing a semi-rigid and } \\
\text { flexible ureteroscopy with laser lithotripsy } \\
\text { and the use of an unusual long type of } \\
\text { ureteric stent. }\end{array}$ \\
\hline $\begin{array}{l}\text { Hatzidakis } \\
\text { et al. } 20149\end{array}$ & $\begin{array}{l}\text { 86-year-old female patient with a septic picture } \\
\text { and right ureteric obstruction, caused by a } \\
\text { symptomatic Bochdalek hernia. CT non- } \\
\text { contrast confirmed non-calculus hydronephrosis } \\
\text { and an obstructed herniated ureter. }\end{array}$ & $\begin{array}{l}\text { The patient was initially managed with } \\
\text { percutaneous nephrostomy. The final } \\
\text { treatment was achieved by placement of } \\
\text { an external-internal nephroureteral double } \\
\text { pigtail. }\end{array}$ \\
\hline $\begin{array}{l}\text { Sukumar et al. } \\
201010\end{array}$ & $\begin{array}{l}\text { A } 75 \text {-year-old female with long-standing } \\
\text { hypertension was found to have incidental } \\
\text { hydronephrosis during an assessment of mildly } \\
\text { deranged renal function during an episode of } \\
\text { upper respiratory infection. CT and retrograde } \\
\text { pyelogram showed a small non-obstructing } \\
\text { kidney and confirmed Bochdalek hernia with } \\
\text { a classical ureteral loop within the ipsilateral } \\
\text { intrathoracic cavity. }\end{array}$ & $\begin{array}{l}\text { The patient and attending urologist agreed on } \\
\text { non-surgical treatment. }\end{array}$ \\
\hline
\end{tabular}

of the distal stent into the ureter, and that the ureter appeared increasingly dilated. The ureteric stent's re-insertion was undertaken following ureteroscopic assessment, allowing insertion of the guidewire into the renal pelvis under vision. A longer ureteric stent with a double pigtail was then inserted in a standard fashion. The patient experienced significant stent symptoms, and this, in combination with difficulties in stent exchange, led to an alternative approach. Lin et al. opted to perform an open repair of the thoracic hernia and a reduction pyeloplasty with nephropexy for the redundant renal pelvis and ureter. ${ }^{5}$ Shekar et al. however, described a laparoscopic approach to reduce and repair the defect. This was achieved 
by using prolene sutures to close the diaphragmatic defect after reducing the ureter and renal pelvis into the abdominal cavity. The defect was then reinforced with composite mesh. ${ }^{8}$ It was not clear from their case report if a ureteric stent was placed. The authors, while discussing this case with other colleagues, came across an idea of a nephrostomy insertion with a later attempt to realign the proximal herniated and the distal non-herniated ureter by an antegrade stent alone or with an assistance of a retrograde stent (railroading); however this technique was not used by them but can always be considered for urologist coming across similar cases in the future.

The current case report authors have described successful initial intervention with ureteric stent insertion but believe that each case is unique and management is based on multiple factors. Placement of retrograde ureteric stent can be a challenge due to ureteric tortuosity and requires both skill and experience.

\section{CONCLUSION}

Thoracic ureteric herniation is a rare clinical and radiological diagnosis special consideration for managing this unusual incidental phenomenon. This condition can present a significant challenge to the experienced urologist, particularly when there is an infected obstructed kidney driving AKI and sepsis. There is no agreement or available evidence in the literature to suggest a definitive management option for these uncommon cases. The authors recommend a multi-disciplinary approach for its management that is further tailored according to the patient's general holistic needs and the patient's risk factors.

\section{REFERENCES}

1. Catalano O, Nunziata A, Cusati B, Siani A. Retrocrural loop of the ureter: CT findings. AJR Am J Roentgenol 1998;170(5):1293-4.

2. Swithinbank AH. Intrathoracic deviation of a ureteric loop. Br J Surg 1958; 45(192):379-81.

3. Dru CJ, Josephson DY. Bochdalek-type Diaphragmatic Hernia Leading to High-grade Kidney Obstruction. Urology 2016;97:e17-8.

4. Song YS, Hassani C, Nardi PM. Bochdalek hernia with obstructive uropathy. Urology 1338;77(6).

5. Lin FC, Lin JS, Kim S, and Walker JR. A rare diaphragmatic ureteral herniation, case report: endoscopic and open reconstructive management; BMC Urology 2017;17:26

6. Leah E. Beland, Mark A. Henry, Tania Solomon, Kenneth Ogan. Obstructing nephrolithiasis in an 84-year-old patient with a diaphragmatic herniated ureter. Urology 2019;124:e1-e3.

7. Sukumar S, Kumar PG, Thomas A. Thoracic curlicue: A case of ureteral herniation. Indian J Urol 2010;26:131-32.

8. Ashwin Shekar P, Reddy D, Kochhar G, et al. herniation of the right renal pelvis through a posterolateral diaphragmatic defect (BochdalekHernia). Urology 2020;137:e10-e11.

9. Hatzidakis A, Kozana A, Glaritis D, and Mamoulakis C. Right-sided Bochdalek hernia causing septic ureteric obstruction. Percutaneous treatment with placement of a nephroureteral double pigtail. BMJ case reports. 2014;10.1136/bcr-2014-207247.

10. Sukumar S, Kumar PG, Thomas A. Thoracic curlicue: A case of ureteral herniation. Indian J Urol 2010 Jan-Mar;26(1):131-2. 